\title{
A Method for Effective IT Project Risk Management
}

\author{
Malaya Nayak
}

\begin{abstract}
In this paper we introduce a project risk control strategy that is developed regarding IT organizations, requiring them to operate their projects having further securities along with regular procedures. Successful completion of these projects is essential for their advancements, like process improvement, market adaptation and new regulation, including the integration of information and control systems, etc. Often, project managers are not real strategic planning experts, however, the projects will have to still be driven by limited paperwork with sufficient opportunity to be autonomous. This paper attempts to build a method with a comprehensive investigation throughout a large proportion of IT companies regarding the project risk reduction strategy described herein. This approach is focused on risk evaluation and management of IT projects within the organizations, which, provides easy, suggested steps as well as recommended methods, models and threat check-lists. Results were evaluated by5 successful IT project managers dealing in categories of IT business including software engineering firms from different attributes (creativity, software solutions as well as ICT frameworks).
\end{abstract}

Keywords: IT firms; Project risk management; Risks evaluation.

\section{INTRODUCTION}

As software are increasingly in use in organizations to help their businesses, it gets further necessary to protect Information Technology (IT) projects from various risks. Increasing threats may be a loss, particularly for firms who rely on IT project development, also applied to the sole existence of the enterprise. The sooner they realize about their risks, the safer their businesses run. Consequently, handling IT vulnerabilities throughout an organization is necessary to reduce failure incidents as well as provide counter-measures to efficiently find solutions. These firms are also the key tools for transformation, wherein, even outside the regular work routines, the risk assessment of projects is pursued. However, these are often poorly operated or being controlled by inadequate employees. These IT firms usually don't use the current widely accepted project risk evaluation principles (e.g. PMBoK or ICB), but in certain situations born out of ignorance or comparatively uncertainties, even due to their limited project personnel.

The paper has been focused on 5 particular IT projects that were developed as well as analyzed, to introduce a risk assessment approach for IT projects specifically modeled for those cases where uncertainties are common (Pérez-

Revised Manuscript Received on February 05, 2020.

* Correspondence Author

Malaya K. Nayak*, Executive Director, IT Buzz Ltd and U-Com Software Private Ltd. Pune, Maharashtra, India.

(C) The Authors. Published by Blue Eyes Intelligence Engineering and Sciences Publication (BEIESP). This is an open access article under the CC BY-NC-ND license (http://creativecommons.org/licenses/by-nc-nd/4.0/)
Ezcurdia and Marcelino-Sádaba, 2012). Figure 1 demonstrates the schematic approach adopted by this study Through a literature review, a description of specific requirements, as well as interpretations of device attributes, was conducted in conjunction with IT project management companies. We also built a framework to conduct control activities on the basis of results as well as producing model assistance for 50 test organizations.

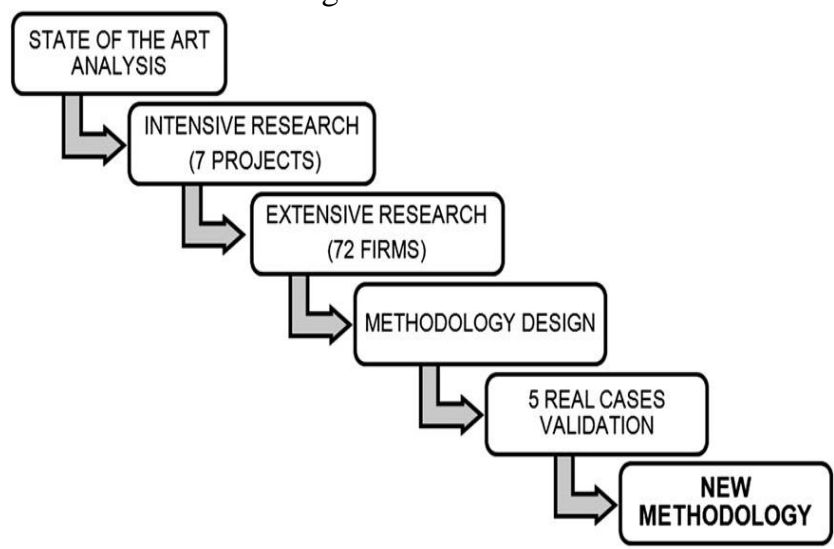

Fig 1.Investigation phases

Additionally, this technique has been empirically developed and tested for 5 IT programs. Parameters for the classification of organizations as well as the selection of activities included the broadest variety of groups as well as the form of IT projects (Standard projects, ERP application, product documents, information systems, etc.).

\section{LITERATURE REVIEW}

For most scenarios, productivity is achieved via the integration of projects by businesses as well as software development firms. Such activities can aim to fulfill the requirements against which new problems need to be resolved as well as to develop resources that promote such an approach. Software development firms, though, experience extreme challenges in carrying out projects particularly about generating profits or pursuing better innovations.

Because the effectiveness of software development organization is continuing to be greater, the creativity in software development companies is still widely discussed (Tomlinson and Fai,2013). Many reports also take account of the value of exposure to enterprise applications for project management companies to address scarce technology and resources, thereby enabling expanded technical possibilities (Tomlinson and Fai, 2013). 
Project management through risk management documentation was available, although in different organizations including independent IT project management companies there seems to be insufficient data for managing project risks. Risk management within project management is indeed a systemic method designed to detect and reduce risks or respond to its introduction in terms of processes or protocols to recognize, assess, determine as well as resolve the threats which are intrinsic to the projects (Bush et al., ).

Throughout the risk assessment phase, several researchers deem risk detection to be the foremost essential component because once the vulnerability has been detected, action can be taken for its elimination. Project frameworks are essentially vulnerable owing to several risk forms that prevent these from being completely identified.

According to Yen and Sheu (2004), the loss of an IT company's projects could have a major effect on the outcomes. For most others, that is because the initiative is not compatible with that of the mid to long-term goals of the organization. Software development companies require adequate methods as well as instruments to reduce potential adverse implications (Marcelino-Sádaba and PérezEzcurdia, 2010; Unionpyme, 2007).

Different priorities to assist project management were produced to establish rules and procedures (APM, 2004; AFNOR, 2003; IPMA, 2006; IRM, 2002; OGC, 2007; OGC, 2008; TSO, 2009), that would allow the highest possible excellence to be achieved, via choose and re-use, of the goals (Sanchez et al., 2009). Managing risks was designed exclusively for the large-scale project management principles, hence, its application involved at least some change to the realities of non-project-oriented IT organizations since various risks mitigation exercises are essentially non-scalable.

\section{METHODOLOGY AND DESIGN}

\section{A. Requirement of Risk Management}

The preliminary study described problems with new ventures that IT Companies face. Towards this extent, 5 separate IT projects carried out were examined having their potential reasons and anomalies established (MarcelinoSádaba and Pérez-Ezcurdia, 2010). We also accomplished a few prerequisites which should be fulfilled by the new methods and resources.

A comprehensive survey was conducted in conjunction with a software company during 2018-2019 in numerous IT Project Management Organizations, where we had discussions including specific meetings regarding this study (Table 1). Referring to the PMBoK's (PMI, 2008) indicators of performance in risk assessment, project management organizations ought to be directed and provided a wider range of risk management resources. Its techniques are embedded throughout this approach by an operating process, wherein the project's impacts will be recognized beginning out of a motive for success.

In the PMBoK (2008) its PMI segregates the project into 3 steps: start-up/start, mid-term and end-start (Heldeman 2002); 5 phase types are taken into account, namely the introduction, managing, implementation, monitoring and closure activities. The approach suggested is therefore split between 4 different steps: identifying, preparing, carrying out, reporting, and closing including evaluation of outcomes. Figure 2 portrays the connection amongst the design steps as well as the new analysis, which is premised upon the life-cycle of PMI (2008). Figure 3 includes the layouts used as well as the events to be carried out, the records produced from each pattern.

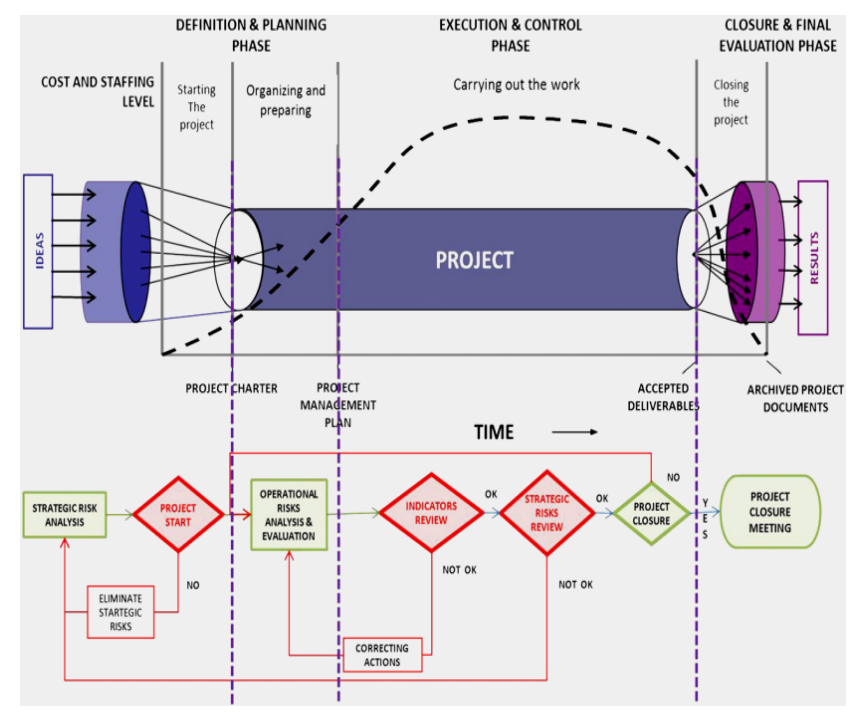

Fig 2.Proposed risk management strategy for projects (adopted from PMI, 2008)

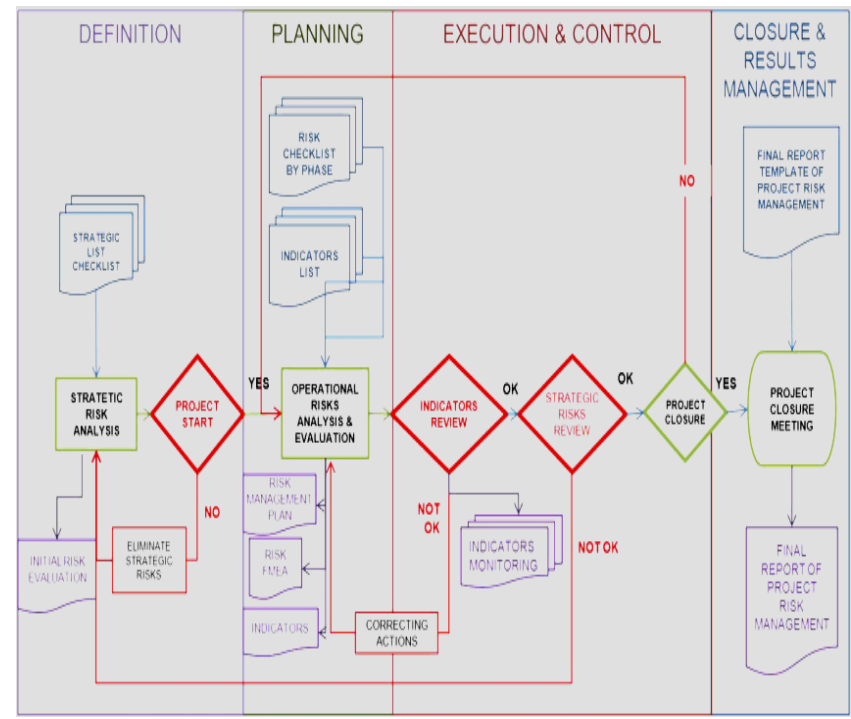

Fig 3.Proposed method and assessment documentation for projects

\section{B. Identifying risks related to projects}

Determination of threats in the project design process is a crucial activity as the hazards to be identified are competitive and therefore should be eliminated before the start of every project. All who materialize could contribute to projects' loss explicitly and perhaps even the very sustainability of the organization is deemed competitive to such threats. In order to predict and prepare threats, the things that need to be adequately described but whose lack does have a significant effect on the final outcomes must be listed. 
Such data needs to be verified so that security threats can also be evaluated before project delivery.

\section{Planning and Design}

This phase includes 3 activities:

Identification of a risk management strategy: Identification of the level of metrics monitoring defined threats and the concerned individuals for that is a significant part of the risk assessment strategy. Both staff members must include the explanation of such things. For instance, the approach suggested involves a basic risk strategy, including activities, accountable, intensity management including documents created.

Administrative risk evaluation: This aims to identify many of the issues involved with design tasks (operative threats) which may occur throughout projects. While these include failing to meet such targets, these may not place the entire project including the business in trouble. The method envisages various standard risks identified within the project development stage wherein they normally occur to assure that such a classification stage is carried out with minimum errors.

Risk assessment and review: This includes not just the risk assessment at the start of the projects (which is important during that time), however, a routine review is required unless the project is extended or major schedule transformations occur. The key component in this job would be the "Failure Modes and Effects Analysis" (FMEA), which is widely used by industry to identify, evaluate and deter goods plan and manufacturing inadequacies.

Figure 4 represents the Willams_M_o_R approach for defining risk assessment plans. In relation to these assessment criteria of severity and likelihood, the risk management plan of action is recommended.

Monitoring and control of risks' status: This activity includes reviewing operational risk indicators and periodically reviewing the project's strategic risks, already identified in the definition phase.

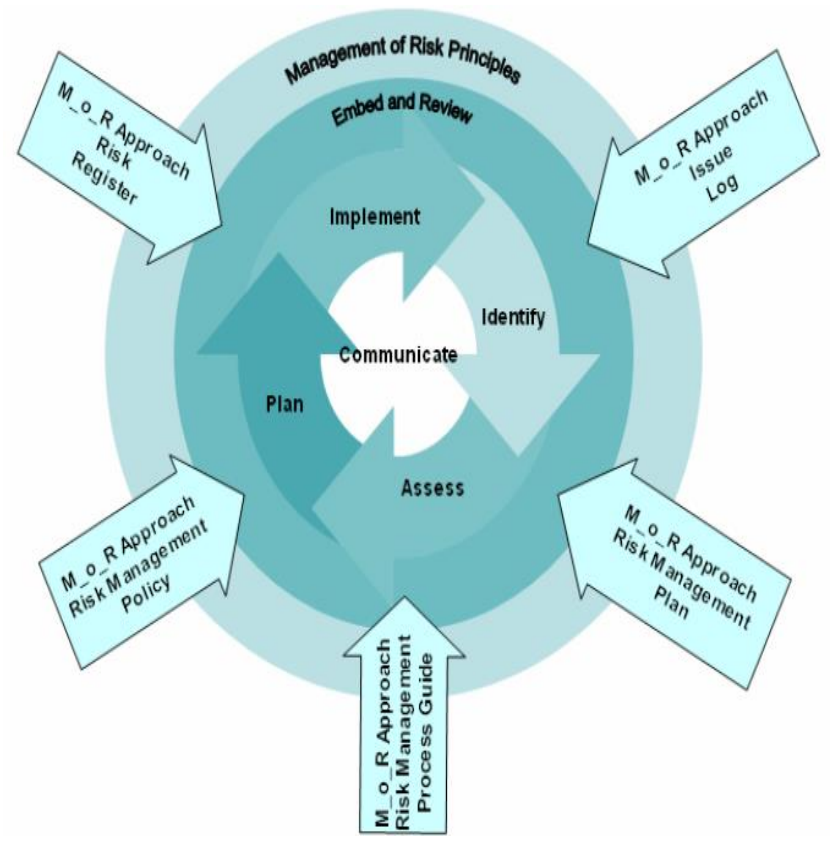

Fig 4.Risk assessment plan (adopted from Willams' M_o_R strategy, 2007)

\section{Project results management}

Firstly, the recognition of the expertise produced throughout the design is a decent result analysis. In an attempt to circulate it positively or negatively, it is essential to analyze that this information can be stored and if its safety can be supplied. Since learning is actively carried out during the project's lifespan (classification, preparation, implementation, and finalization), this approach aims to do so throughout the duration of this process.

\section{VALIDATION OF METHOD}

Some experiments were required to evaluate the validity of the proposed risk assessment approach. Many of the organizations which participated in this analysis conducted the rules for projects selected. For this reason, a technical roadmap has been developed with all the details needed to address a project manager's risks: basic principles of project planning, modern methods, phase of execution, diagrams, flow charts, etc. For instance, 4 individuals participated in the project's design and development group. Regardless of the specific qualities of the project managers, the execution was successfully implemented. Firstly, the objective of such deployments was to determine the validity and effectiveness of the approach. We also wanted to learn whether the failure to understand, the conflicts among the standards of the organization as well as the request received, or the wrong software method implemented not using any resources may be the reason. The research was structured as represented by figure 5 when the organizations, as well as projects, have been selected with their cooperation established. A significant number of enhancements including from perceptual manifestations to visual elements in the suggested models were made possible by implementing the qualitative guideline (Table 2).

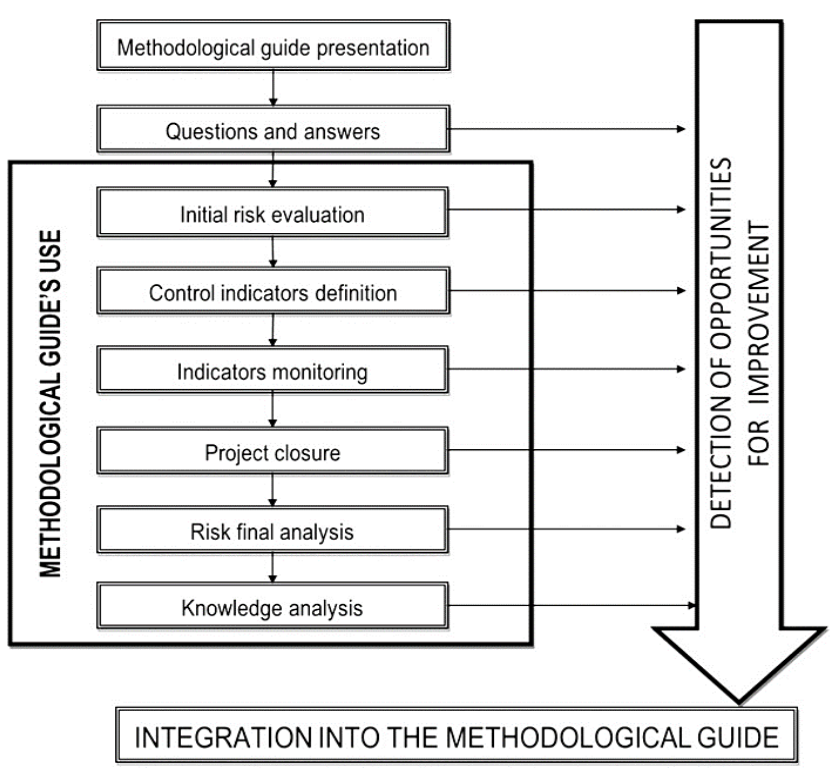

Fig 5.Integration of the proposed method 
Table 1.Proposed parameters for project management firms

\begin{tabular}{|l|l|l|l|}
\hline Stages & Actions & Methods & Checklists \\
\hline $\begin{array}{l}\text { Identification } \\
\text { Planning }\end{array}$ & $\begin{array}{l}\text { Planned risk analysis and estimation } \\
\text { Risk management planning } \\
\text { Operational risk analysis and evaluation }\end{array}$ & $\begin{array}{l}\text { Strategic risk checklist } \\
\text { Scheduling prototype } \\
\text { Phase risk checklist FMEA }\end{array}$ & $\begin{array}{l}\text { Initial risk assessment } \\
\text { Risk planning Risk FMEA }\end{array}$ \\
\hline Execution \& control & $\begin{array}{l}\text { Indicators' description } \\
\text { Indicators' review } \\
\text { Correcting actions } \\
\text { Strategic risk review }\end{array}$ & $\begin{array}{l}\text { Indicators' checklist Indicators' list } \\
\text { Risk planning } \\
\text { Strategic risk checklist } \\
\text { FMEA }\end{array}$ & $\begin{array}{l}\text { Indicators' list } \\
\text { Updated indicators' list } \\
\text { Updated risk planning } \\
\text { Updated risk FMEA }\end{array}$ \\
& $\begin{array}{l}\text { Project closure decision Closure report } \\
\text { approval }\end{array}$ & $\begin{array}{l}\text { Meeting } \\
\text { Checklist of risks related to results } \\
\text { administration }\end{array}$ & Project results report \\
\end{tabular}

\section{RESULTS AND DISCUSSION}

Project managers with prior experiences with software development and to use the technique indicated less complexity than those in past incidents as well as the money spent in applying the guidance was worth its impact. There had never been more than 80 hours spent using the technique. This also ensured cost-cutting as time and failure both were reduced by this approach. The association of this approach indicates a reduction of risks also relationship of costs and the task completion time was $4.76 \%$ (15 days of the month, including 8 hours daily). Moreover, the percentage increased as the project's completion time reduced. The approach was therefore beneficial not only during its use to assess risks but, also in controlling failures, costs and focusing of skilled project planning. It indicated that across all stages of the project development phases, the strategy can be introduced.

- A few other beneficial aspects of the approach are:

- It required competitive threats to be minimized and goals to be described accurately, removing significant mission design defects.

- This allows quick and visually objective decisions on the state of the task threats.

- The suggested model is pragmatic and convenient in use

\section{CONCLUSIONS}

An IT project risk-management framework appropriate for IT organizations that assists in the development of a tactical strategy is the major impediment of this work and therefore is supported by consistent application success methods and practices as suggested. Such an approach extends across all project processes, moreover, can be applied to multiple projects as well as businesses. However, it needs very little money, demands no special planning, delivers adept decision-making input and incorporates control of expertise as well as performance.

A description of IT tasks planning including necessary balancing among success as well as shortcomings is given by the process. This enables knowledge to be produced to guarantee that interactions with learning are therefore not returning to these same failures or challenges. This offers simple and easy resources like risk assessments, models, FMEA benchmarks and provides efficient and productive risk governance.

\section{FUTURE SCOPES}

The variable control which is a feature that enables the prediction and evaluation of the risk management should be carried out in the future. The risk measure for a project must be established to handle the threats efficiently by determinants:

- Determining risk indicators

- Profitability for stabilization and risks

- Rate of reviews.

\section{REFERENCES}

1. Association for Project Management, 2004. Project Risk Analysis and Management Guide, 2nd Edition. APM Publishing Limited, UK.

2. Bannerman, L., 2008. Risk and risk management in software projects: a reassessment. Journal of Systems and Software 81, 2118-2133.

3. Bush, J.K., Dai, W.S., Dieck, G.S., Hostelley, L.S., Hassall, T., 2005. The art and science of risk management-a US research-based industry perspective. Drug Safety 28 (1), 1-18.

4. Chapman, C.B., Ward, S., 2007. Project Risk Management: Processes, Techniques, and Insights. School of Management, University of Southampton, UK0-470-85355-7.

5. Delisle, S., St-Pierre, J., 2003. IT firms projects: software for the identification, asses IT firms and management of risks. 48th World Conference of the International Council for IT company (ICSB-2003). ICSB, Belfast, Ireland.

6. Entrialgo,M., Fernández, E., Vázquez, C.J., 2001. The effect of the organizational context on IT firms's entrepreneurship: some IT evidence. IT company Economics 16, 223-236.

7. European Commission, 2008. The New IT firms Definition: User Guide and Model Declaration. Enterprise and Industry Publications, European Union Publications Office.

8. Grant, K.P., Cashman, W.M., Christensen, D.S., 2006. Delivering projects on time. Research \& Technology Management 52-58 (November-December).

9. Hashi, I., Stojcic, N., 2013. The impact of innovation activities on firm performance using a multi-stage model: evidence from the community innovation survey 4. Research Policy 42, 353-366.

10. Heldeman,K.,2002.PMP:ProjectManagementProfessionalStudyGuide. Sybex, Inc., Alameda, CA, USA.

11. International Organization for Standardization, 2012. ISO 21500 Guidance on Project Management.

12. International Project Management Association (IPMA), 2006. The IPMA Competence Baseline, ICB 3.0. IPMA, The Netherlands.

13. IRMIC, ALARM, IRM, 2002. A Risk Management Standard. The Institute of Risk Managers, UK.

14. Kerzner, H., 2011. Project Management Metrics, KPIs, and Dashboards. John Wiley \& Sons, Inc., New Jersey, USA.

15. Klomp, L., Van Leeuwen, G., 2001. Linking innovation and firm performance: a new approach. International Journal of the Economics of Business3,343-364. Lee, S.,

16. Park, G., Yoon, B., Park, J., 2010. Open innovation in Project Management Firms -An intermediated network model. Research Policy 39, 290-300.

17. Malhotra, R., Temponi, C., 2010. Critical decisions for ERP integration: small business issues. International Journal of Information Management 30, 28-37. 
18. Marcelino-Sádaba, S., Marhavilas, P.K., Koulouriotis, D., Gemini, V., 2011. Risk analysis and assesIT firms methodologies in the worksites: on a review, classification and comparative study of the scientific literature of the period 2000-2009. Journal of Loss Prevention in the Process Industries 24, 477-523.

19. Marle, F., 2011. Interactions-based risk clustering methodologies and algorithms for complex project management. International Journal of Production Economics. http://dx.doi.org/10.1016/j.ijpe.2010.11.022.

20. Pérez-Ezcurdia, A., Marcelino-Sádaba, S., 2012. The small project paradox in Project Management Firms. Prime Journal of Bussiness Administration and Management 2 (9), 687-692.

21. PMI-Project Management Institute, 2008. A Guide to Project Management.

22. Rowe, S.F., 2007. Project Management for Small Projects. Management Concepts, Inc., USA.

23. Sánchez, H., Robert, B., Bourgault, M., Pellerin, R., 2009. Risk management applied to projects, programs, and portfolios. International Journal of Managing Projects in Business 2 (1), 14-35.

24. Schmidt, R., Lyytinen, K., Keil, M., Cule, P., 2001. Identifying software project risks: an international Delphi study. Journal of Management Information Systems 17 (4), 5-36.

25. Taylor, H., 2004. Risk factors in vendor-driven IT projects. Tenth Americas Conference on Information Systems, New York, USA, August 5-8, pp. 777-784.

26. Taylor, H., 2005. The move to outsourced IT projects: key risks from the provider perspective. Proceedings of the 2005 ACM SIGMIS CPR conference on Computer Personnel Research, Atlanta, Georgia, USA, April 14-16, pp. 149-154.

27. Taylor, H., 2006. Critical risks in outsourced IT projects: the intractable and the unforeseen. Communications of the ACM 49 (11), 75-79.

28. Taylor, H., 2007. Outsourced IT projects from the vendor perspective: different goals, different risks. Journal of Global Information Management 15 (2), 1.

29. Tomlinson, P.R., Fai, F.M., 2013. The nature of IT firms co-operation and innovation: a multi-scalar and multi-dimensional analysis. International Journal of Production Economics 141 (1), 316-326. http://dx.doi.org/ 10.1016/j.ijpe. 2012.08.012.

30. Vidal, L.A., Marle, F., Bocquet, J.C., 2009. Interactions-based clustering to assist project management. Proceedings of the International Conference on Engineering Design. Design Society, United States of America, Stanford.

31. Wang, J., Lin, W., Huang, Y., 2010. A performance-oriented risk management framework for innovative R\&D projects. Technovation $30,601-611$.

\section{AUTHORS PROFILE}

Dr. Malaya Kumar Nayak, is an Entrepreneur and researcher with over 23 years leading the design, development and implementation of high-performance Executive Director with IT Buzz Ltd and U-Com Software Private Ltd. He has received an M.S degree in ICT from Assumption University and a Ph.D. degree in Computer Science from Utkal University. He has published more than 25 research papers in National \& International Conferences and Journals. His current research interests in project management and risk management. 